\title{
Coseismic slip distribution of the 2011 off the Pacific coast of Tohoku Earthquake ( $M$ 9.0) estimated based on GPS data- Was the asperity in Miyagi-oki ruptured?
}

\author{
Takeshi Iinuma $^{1}$, Mako Ohzono $^{1,2}$, Yusaku Ohta ${ }^{1}$, and Satoshi Miura ${ }^{1,3}$ \\ ${ }^{1}$ Research Center for Prediction of Earthquakes and Volcanic Eruptions, Tohoku University, Sendai 980-8578, Japan \\ ${ }^{2}$ Institute of Seismology and Volcanology, Hokkaido University, Sapporo 060-0810, Japan \\ ${ }^{3}$ Earthquake Research Institute, the University of Tokyo, Tokyo 113-0032, Japan
}

(Received April 19, 2011; Revised June 1, 2011; Accepted June 8, 2011; Online published September 27, 2011)

\begin{abstract}
We investigated the crustal deformation associated with the 2011 off the Pacific coast of Tohoku Earthquake ( $M$ 9.0) that occurred on March 11, 2011, along the plate boundary off Tohoku district, northeastern Japan, based on dense GPS observation. Coseismic displacements due to this event were applied to estimate the causal interplate slip by means of a geodetic inversion analysis. The major slip area is located around the asperities of the 1981 Miyagi-oki (M 7.2) and 2003 Fukushima-oki (M 6.8) earthquakes and the maximum slip is estimated as being up to $35 \mathrm{~m}$. The estimated slip distribution suggests that the asperities of the Miyagi-oki earthquake in 1978 (M 7.4) that had not been ruptured during the Miyagi-oki earthquake in 2005 were ruptured as a part of the main shock fault of the 2011 off the Pacific coast of Tohoku Earthquake.
\end{abstract}

Key words: 2011 off the Pacific coast of Tohoku Earthquake, interplate earthquake, GPS, slip distribution, Miyagi-oki earthquake.

\section{Introduction}

The 2011 off the Pacific coast of Tohoku Earthquake (M 9.0) occurred on 11 March, 2011, off the Pacific coast of Tohoku district, northeastern Japan, where the Pacific plate is subducting at a rate of about $70 \sim 85 \mathrm{~mm} /$ year beneath the overriding continental plate (Altamimi et al., 2007). The plate interface between the Pacific and the overriding continental plates around the Tohoku district is one of the most active areas of seismicity in the world. Various studies of major interplate earthquakes around this area have revealed that some of those events can be regarded as recurrent ruptures of asperities, which are defined by distributed patches showing large coseisimc slip (e.g., Nagai et al., 2001; Yamanaka, 2003; Yamanaka and Kikuchi, 2003, 2004). The rupture area of the 2011 Tohoku Earthquake includes several asperities of $M \sim 7$ earthquakes offshore of Ibaraki-Fukushima-Miyagi-Iwate prefectures according to preliminary results of seismological and geodetic data analyses (e.g., Ito et al., 2011; Yagi and Nishimura, 2011; Yamanaka, 2011; Tobita et al., 2011)

Earthquakes with magnitudes of about $7.4 \sim 7.5$ have repeatedly occurred on the plate boundary east of Miyagi prefecture (Miyagi-oki) with an interval of about 37 years. The most recent one took place in 1978, i.e., the $M 7.4$ Miyagi-oki earthquake (e.g., Seno et al., 1980; Umino et $a l .$, 2006). Based on historical records of these recur-

Copyright (c) The Society of Geomagnetism and Earth, Planetary and Space Sciences (SGEPSS); The Seismological Society of Japan; The Volcanological Society of Japan; The Geodetic Society of Japan; The Japanese Society for Planetary Sciences; TERRAPUB.

doi:10.5047/eps.2011.06.013 rent earthquakes, the Headquarters for Earthquake Research Promotion (2011) stated that the next Miyagi-oki earthquake will occur with a probability of about $70 \%$ in the next 10 years from 1 January, 2011.

On August 16, 2005, there occurred an interplate earthquake with magnitude 7.2, hereafter referred to as the 2005 Miyagi-oki earthquake. Okada et al. (2005) carried out the relocation of aftershocks of the 1978 and 2005 events to reveal that the aftershock area of the 2005 event overlaps only with the southeastern part of the 1978 source area. Yaginuma et al. (2006) performed seismic waveform inversion for the 2005 event to estimate the coseismic slip distribution and found that it also corresponds to the southeastern part of the 1978 rupture area. The northern and southwestern parts of the rupture area of 1978 earthquake did not slip aseismically after the 2005 earthquake (Miura et al., 2006; Iinuma et al., 2011). Therefore, it was considered that the remaining asperities of the 1978 Miyagi-oki earthquake had not been ruptured and had been accumulating strain energy since 1978 for the next Miyagi-oki earthquake, until the 2011 earthquake occurred.

Here, we consider the problem as to whether the remaining asperities of the 1978 Miyagi-oki earthquake ruptured with the 2011 off the Pacific coast of Tohoku Earthquake, or not, based on land GPS observation data. In the present study, we use GPS data to estimate coseismic slip distributions on the plate boundary by means of a geodetic inversion method.

\section{Data and Analysis}

Tohoku University has been conducting continuous GPS observations in the Tohoku district since 1987 (Miura et 

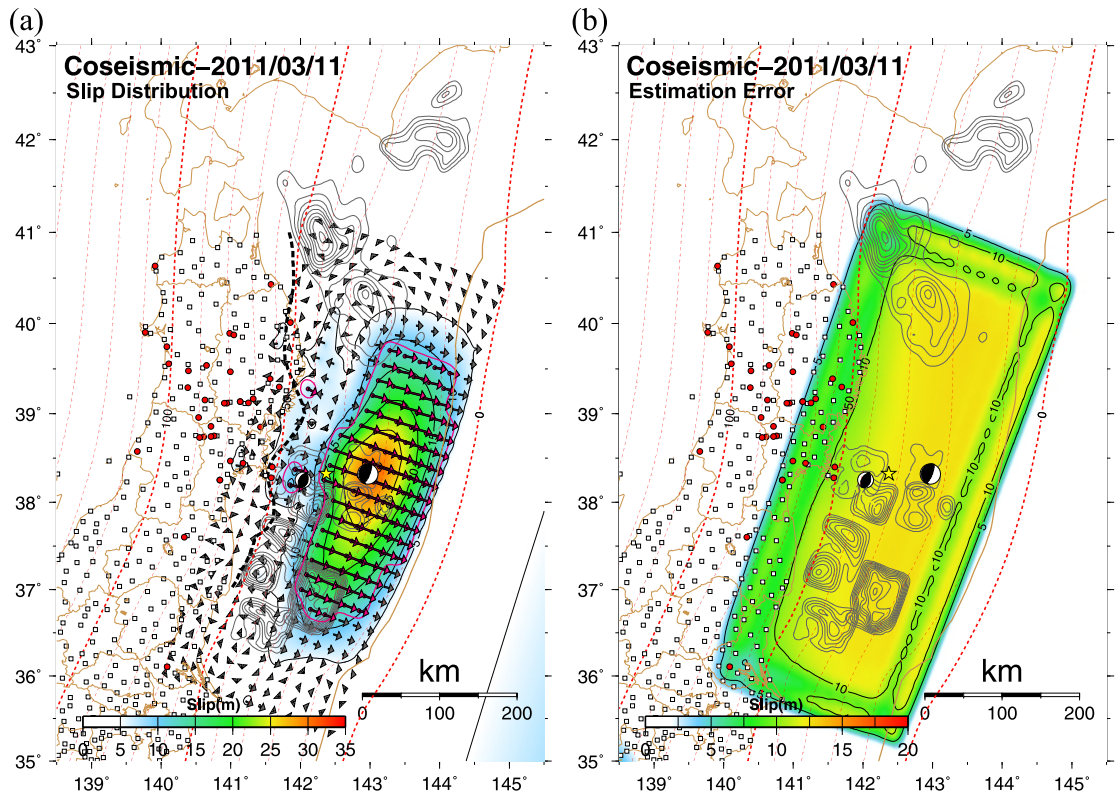

Fig. 1. (a) Coseismic slip distribution estimated from observed displacements at all GPS stations. Arrows denote slip vectors on the hanging wall of the plate interface. Contours of the interplate slip are also shown with a color scale. The contour interval is $5 \mathrm{~m}$. Purple arrows and the areas surrounded by the purple solid lines indicate that here the estimated values are greater than the estimation errors. White squares and red circles denote GPS stations conducted by the GSI and Tohoku University, respectively. The black dashed line denotes down-dip limit of interplate earthquakes determined by Igarashi et al. (2001). The broken red lines show the depth of the subducting plate interface. The epicenter of the main shock and mechanism solutions of the main shock and an aftershock on 7 April, 2011, (M 7.1) estimated based on W-phase inversion analysis are indicated by a yellow star and the beach-ball symbols (USGS, 2011a, b). The gray contours denote the slip areas for recent major earthquakes at Tokachi-oki in 2003 (Yamanaka and Kikuchi, 2003) and 1968, Miyagi-oki in 1978, 1981 and 1936 (Yamanaka and Kikuchi, 2004), Fukushima-oki in 2003 (Yamanaka, 2003) and 1938 (Murotani, 2003). The thin brown lines denote the prefectural borders. (b) Estimation error distribution. The contour interval is $5 \mathrm{~m}$.

al., 1993). The GPS observation network of Tohoku University spatially interpolates the nationwide GPS network, GEONET, which is managed by the Geospatial Information Authority of Japan (GSI). We can improve the spatial resolution of the inversion analysis to estimate the coseismic slip distribution especially around the Miyagioki region by using GPS data observed at 383 sites of not only GSI (345 sites) but also Tohoku University (38 sites). Ohzono et al. (2011) estimated the site coordinates before and after the mainshock by using Bernese GPS Software version 5.0 (Dach et al., 2007), and calculated coseismic displacements by taking the differences between the daily site coordinates of before and after the mainshock, namely on March 10 and 11 (after 5:47 on GPS time). Refer to Ohzono et al. (2011) for further details of GPS observation and data processing.

We estimated the coseismic slip distribution based on the displacement field determined by Ohzono et al. (2011), using an inversion method proposed by Iinuma (2009). In this inversion method, the weights of three constraint conditions, namely, spatial smoothing, initial value damping, and the boundary condition are optimized by minimizing Akaike's Bayesian Information Criterion (ABIC) (Akaike, 1977, 1980). We applied a plate-boundary model estimated by Nakajima and Hasegawa (2006) to model the plate interface fault. Vertical and horizontal displacements are equally weighted in the inversion analysis, because the modeling errors due to the uncertainty and heterogeneity of the physical properties of the crust, such as rigidity and Poisson's ratio, the error of the geometry of the plate-interface fault, the effect of the terrain topography, and so on, must exceed the observation errors at most GPS stations.

\section{Results and Discussion}

Estimated slip vectors on the hanging wall of the plate interface are shown by arrows and contours with an interval of $5 \mathrm{~m}$ in Fig. 1. The coseismic slip is centered around the moment tensor solution based on W-phase analysis performed by the US Geological Survey (USGS) (2011a) denoted by a beach-ball symbol. Looking at the area of major slip shown by the contour of $30 \mathrm{~m}$, it overlaps the asperities of the 1981 Miyagi-oki earthquake (Yamanaka and Kikuchi, 2004) and the 2003 Fukushima-oki earthquake (Yamanaka, 2003). The total seismic moment obtained by integrating the distributed slip shown in Fig. 1 amounts to $4.0 \times 10^{22} \mathrm{~N} \mathrm{~m}$, which is equivalent to a moment magnitude of 9.0 and almost identical with the value determined by the Japan Meteorological Agency (JMA) (2011a).

The area of significant slip, where the slip is larger than the estimation error (surrounded by purple lines in Fig. 1), is divided into two areas. One is the main rupture area on the plate interface shallower than $30 \mathrm{~km}$ in depth, where the subducting plate is in contact with the crust of the continental plate. Another is located at the Miyagi-oki region where the asperities that caused the 1978 Miyagi-oki earthquake are distributed. The hanging-wall side of the plateinterface fault is the continental mantle at the Miyagi-oki region. We can conclude that tremendous slip in the crustcrust contact zone on the plate boundary mainly caused the 2011 off the Pacific coast of Tohoku Earthquake, and that the boundary between the continental crust and the mantle on the hanging-wall side of the plate interface fault might 

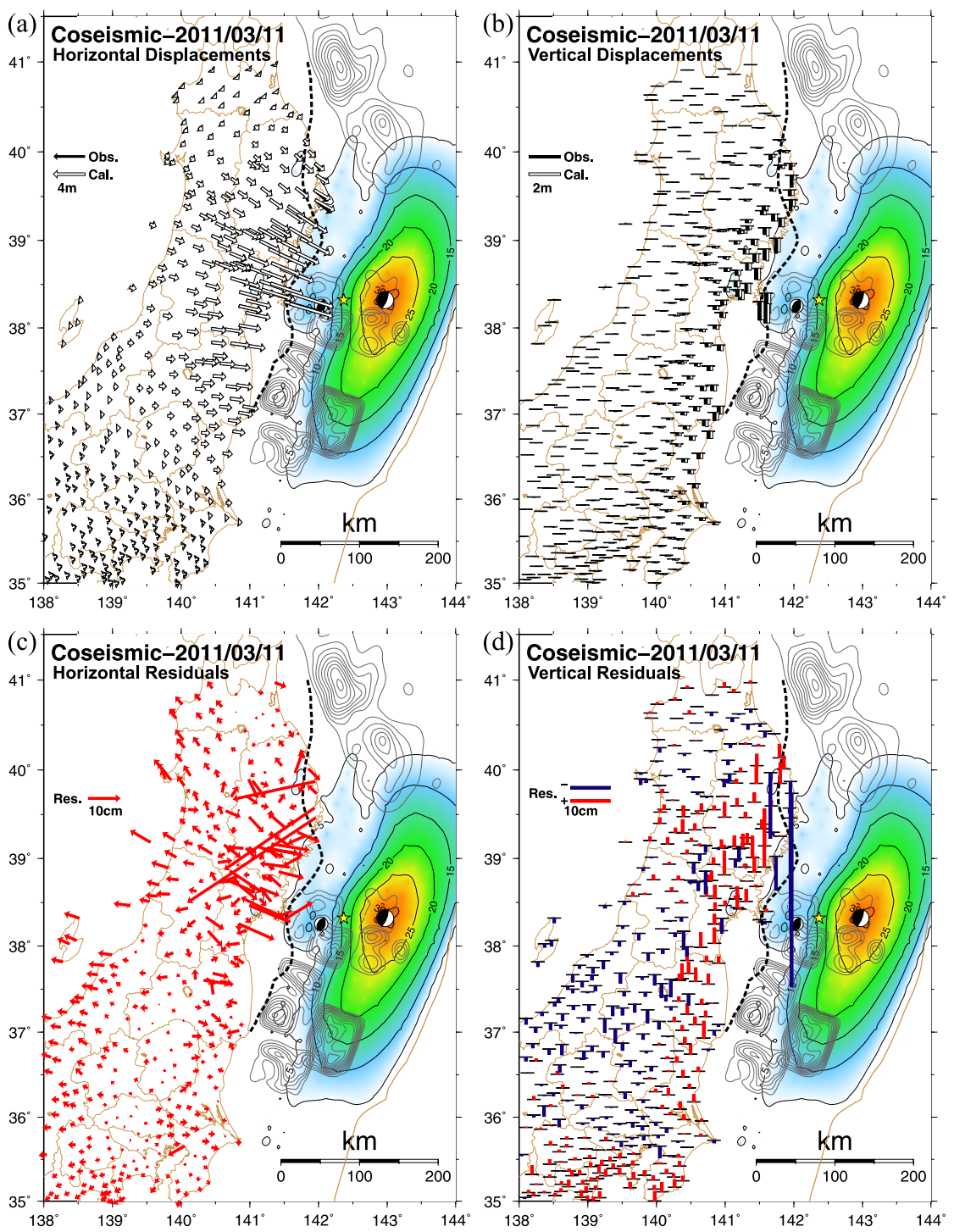

Fig. 2. Comparison between observed displacements (black arrows in (a) and bars in (b) ) and calculated ones (white arrows in (a) and bars in (b) ) from the estimated coseismic slip distribution. (a) Horizontal component and (b) vertical component are shown with their residuals ((c) and (d)). The residuals are calculated by subtracting the calculated displacement from the observed displacement for each site.

prevent the main-shock rupture from propagating into the crust-mantle contact zone along the plate interface. Miyagioki, however, is an exceptional region where coseismic slip also has occurred on the plate interface under the continental mantle. The heterogeneity of the mantle wedge might control this slip heterogeneity in the crust-mantle contact zone as Yamamoto et al. (2008) suggested. Yamamoto et al. (2008) found that the mantle wedge above the coseismic slip area of the 1978 Miyagi-oki earthquakes is characterized by high $V_{p}$ and $V_{s}$, but low $V_{p} / V_{s}$, which they interpreted as indicating a less-serpentinized state, while $V_{p} / V_{s}$ is high at the updip end of the mantle wedge in the Fukushima-oki region possibly because of extensive serpentinization. Therefore, the elastic-strain energy can be accumulated in the asperities in the Miyagi-oki region, and is released by causing seismic slip.

Slip up to $15 \mathrm{~m}$ is estimated around the western and northern asperities of the Miyagi-oki earthquake in 1978, and the estimated values in this region are greater than the estimation error. This result indicates that the remaining asperities of the Miyagi-oki earthquake were ruptured with the occurrence of the 2011 off the Pacific coast of Tohoku Earthquake. However, the slip amount is too large to be accounted solely by the cumulative slip deficit since 1978 , if the slip deficit was reduced to zero by the 1978 earthquake. The cumulative slip deficit should be no more than $3 \mathrm{~m}$, because the plate convergence rate $(70 \sim 85 \mathrm{~mm} / \mathrm{year})$ times the lapse time since the 1978 Miyagi-oki earthquake (about 33 years) is equal to about $2.3 \sim 2.8 \mathrm{~m}$ even if the plate interface is fully coupled during the whole interseismic period. Further investigation is therefore required to balance the budget of slip and slip deficit.

The estimated slip distribution suggests that the main shock rupture did not propagate into the brittle-ductile transition zone along the plate interface. Igarashi et al. (2001) pointed out that there is a clear boundary of the distribution of the interplate earthquakes in this region, which is indicated by the dashed line in all figures in this paper, and no slip is estimated at the plate interface deeper than this border. However, weak interplate coupling has been estimated 


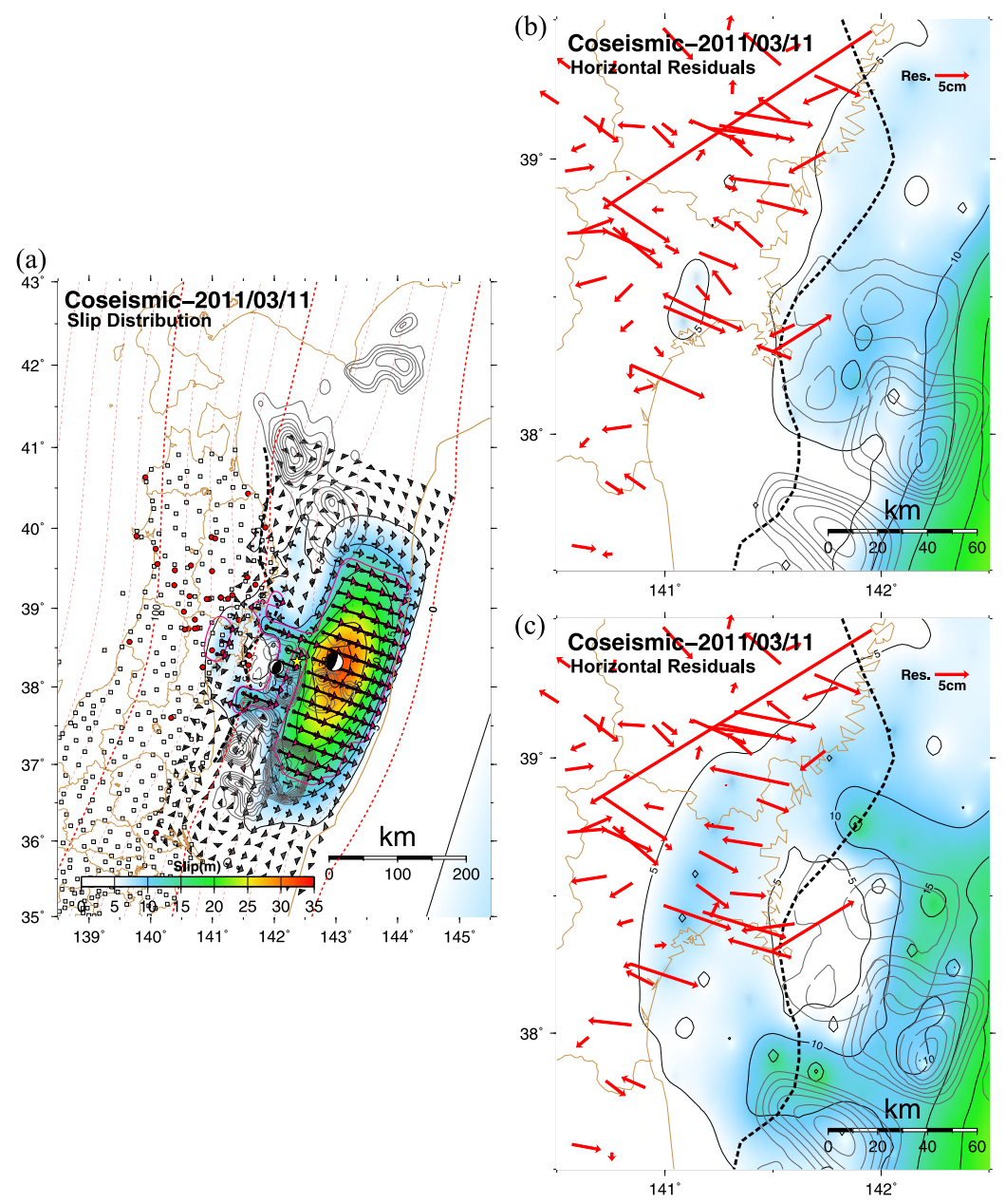

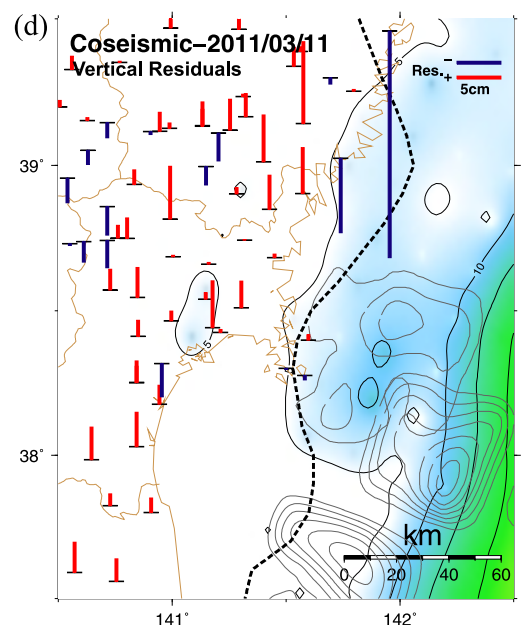

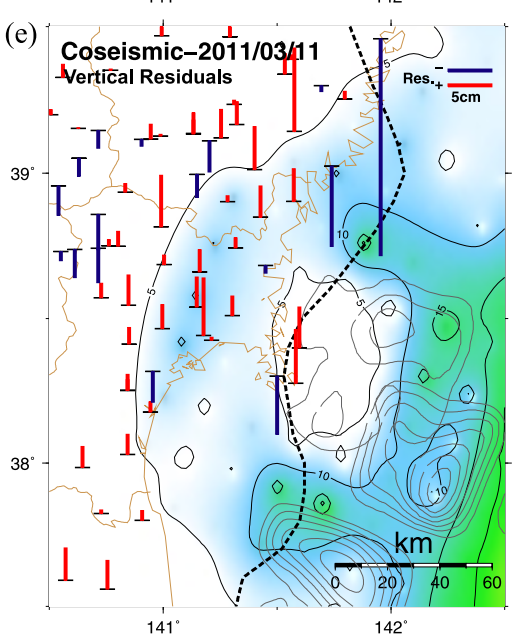

Fig. 3. The results when we imposed an additional condition that the slip in the Miyagi-oki region is constrained to be zero, and the comparison of the residuals between the optimum and the constrained models. (a) Coseismic slip distribution is presented as in Fig. 1(a). The distributions of the residuals of the horizontal components ((b) and (c)) and of vertical displacements ((d) and (e)) around the Miyagi-oki region are displayed. The residuals are calculated by subtracting the calculated displacement from the observed displacement for each site. The results based on the optimum model are shown in (b) and (d). (c) and (e) represent the results based on the constrained model.

in the deeper plate boundary based on interseismic crustal deformation data (e.g., Ito et al., 2000; Nishimura et al., 2004; Suwa et al., 2006). Thus, postseismic slip is expected to occur in the plate interface deeper than this boundary in order to release the cumulative strain energy due to the interplate coupling.

An M7.1 aftershock occurred on 7 April, 2011, in the Miyagi-oki region, near the rupture area of the Miyagi-oki earthquake in 1978 (see Fig. 1). This aftershock, however, must have occurred in the subducting Pacific slab according to the moment tensor analyses (USGS, 2011b; JMA, 2011b) and to an analysis of the crustal deformation (Ohta et al., 2011). The epicenter of this aftershock is located in the low slip area between the main rupture area and the rupture area in Miyagi-oki. This heterogeneity of slip distribution may have caused this aftershock due to the stress concentration (Yoshida, personal communication).

We performed another geodetic inversion analysis constraining the slip in the Miyagi-oki region to be zero. The result is shown in Fig. 3. Since the slip in the Miyagi-oki region is excluded, significant slip is estimated in the areas surrounding the Miyagi-oki region, while the main rupture area on the shallow plate interface is almost identical. We can obtain a slip distribution entirely identical to the slip distribution of the optimum model with an ABIC value of -83134 by using the very small $\left(<10^{-17}\right)$ hyperparameter that proportionally controls the weight of the additional constraint condition, while the ABIC is calculated to be -81770 for the constrained model in which the hyperparameter is 1.0. We can conclude that, based on the ABIC values, the model with no additional constraint conditions is better than the constrained model.

Figure 3 presents the comparison of the residual distributions between the results of the optimum and the constrained models. Both horizontal and vertical components of the residuals increase at the sites near the asperity of the 1978 Miyagi-oki earthquake when the additional constraint condition is imposed. In particular, the residuals of vertical displacements are greater than $5 \mathrm{~cm}$ at three sites that are closest to the Miyagi-oki asperities. Two of these three sites are not GSI's, but Tohoku University's, GPS stations (see Fig. 1). It clearly emphasises that the coseismic large slip in the Miyagi-oki region is essential to explain the observed displacement, and that the high density of the GPS observation array is necessary to estimate the precise slip distribution in the spatial resolution of $20 \sim 40 \mathrm{~km}$ on the 
deep $(>30 \mathrm{~km})$ plate interface around Miyagi-oki region.

\section{Summary}

Coseismic deformations associated with the 2011 off the Pacific coast of Tohoku Earthquake were investigated to resolve the causal interplate slips using a dense GPS array data and the geodetic inversion. The major slip area is distributed in the crust-crust contact zone along the plate boundary including the rupture areas of the 1981 Miyagioki and 2003 Fukushima-oki earthquakes. The rupture area of the 1978 Miyagi-oki earthquake must also slip coseismically. We can conclude that the huge earthquake in 2011 includes the Miyagi-oki earthquake, which had been expected to occur in several years time.

Acknowledgments. We would like to thank Professor Jeff Freymueller and Dr. Shin'ichi Miyazaki for their thoughtful reviews of the manuscript. We thank the Miyagi Prefectural government for providing us helicopter flights to collect the GPS data from the Kinkasan and Enoshima islands. Some GPS data were provided by a research project conducted by the Japan Nuclear Energy Safety Organization to establish the evaluation techniques of seismogenic faults. We thank the Geospatial Information Authority of Japan for providing GPS data. The figures were drawn using GMT software (Wessel and Smith, 1998).

\section{References}

Akaike, H., On entropy maximization principle, in Application of Statistics, edited by P. R. Krishnaiah, pp. 27-41, North-Holland, Amsterdam, 1977.

Akaike, H., Likelihood and the Bayes procedure, in Bayesian Statistics, edited by J. M. Bernardo, M. H. DeGroot, D. V. Lindley, and A. F. M. Smith, pp. 143-166, Univ. Press, Valencia, Spain, 1980.

Altamimi, Z., X. Collilieux, J. Legrand, B. Garayt, and C. Boucher, ITRF2005: A new release of the International Terrestrial Reference Frame based on time series of station positions and Earth Orientation Parameters, J. Geophys. Res., 112, B09401, doi:10.1029/ 2007JB004949, 2007.

Dach, R., U. Hugentobler, P. Fridez, and M. Meindl, User manual of the Bernese GPS software version 5.0, 612 pp., Astronomical Institute, University of Bern, 2007.

Headquarters for Earthquake Research Promotion, List of Long-term evaluations of the earthquakes on active faults and subduction zones on 1 January 2011, http://www.jishin.go.jp/main/choukihyoka/ichiran.pdf, 2011 (in Japanese).

Igarashi, T., T. Matsuzawa, N. Umino, and A. Hasegawa, Spatial distribution of focal mechanisms for interplate and intraplate earthquake associated with the subducting Pacific plate beneath the northeastern Japan arc: A triple-planed deep seismic zone, J. Geophys. Res., 106, 21772191, doi:10.1029/2000JB900386, 2001.

Iinuma, T., Discussion on the rank deficiency of the representation matrix of the smoothing constraint in inversion methods using a Bayesian information criterion, J. Geod. Soc. Jpn., 55, 345-353, 2009.

Iinuma, T., M. Sato, N. Uchida, S. Miura, R. Hino, and T. Matsuzawa, Geodetic inversion based on land and seafloor geodetic observation to estimate the spatio-temporal evolution of postseismic slip at Miyagi-oki, offshore Northeastern Japan, Earth Planet. Sci. Lett., 2011 (in revision).

Ito, T., S. Yoshioka, and S. Miyazaki, Interplate coupling in northeast Japan deduced from inversion analysis of GPS data, Earth Planet. Sci. Lett., 176, 117-130, doi:10.1016/S0012-821X(99)00316-7, 2000.

Ito, T., K. Ozawa, T. Watanabe, and T. Sagiya, Preliminary Static fault model of the 2011 M9.0 Honshu Earthquake based on GPS data, http://www.seis.nagoya-u.ac.jp/take/tohoku/2011HonshuEQ.pdf, 2011.

Japan Meteorological Agency, The 2011 off the Pacific coast of Tohoku Earthquake first report $\sim$, http:// www.jma.go.jp/jma/en/News/2011_Earthquake_01.html, 2011a.

Japan Meteorological Agency, A strong aftershock of "The 2011 off the Pacific coast of Tohoku Earthquake" occurred Thursday 7 April, http://www.jma.go.jp/jma/en/News/20110407_aftershock.html, 2011b.

Miura, S., K. Tachibana, K. Hashimoto, E. Murakami, T. Kono, K. Nida, T. Sato, and S. Hori, GPS observation for regional crustal deformation around the northeastern Japan arc, J. Geod. Soc. Jpn., 39, 167-178, 1993.

Miura, S., T. Iinuma, S. Yui, N. Uchida, T. Sato, K. Tachibana, and A. Hasegawa, Co- and post-seismic slip associated with the 2005 Miyagi-oki earthquake (M7.2) as inferred from GPS data, Earth Planets Space, 58, 1567-1572, 2006.

Murotani, S., Rupture processes of large Fukushima-oki Earthquakes in 1938, Master's thesis, The University of Tokyo, 2003.

Nagai, R., M. Kikuchi, and Y. Yamanaka, Comparative study on the source processes of recurrent large earthquakes in Sanriku-oki region: the 1968 Tokachi-oki Earthquake and the 1994 Sanriku-oki Earthquake, Zisin (J. Seismol. Soc. Jpn.), 54, 267-280, 2001 (in Japanese with English abstract).

Nakajima, J. and A. Hasegawa, Anomalous low-velocity zone and linear alignment of seismicity along it in the subducted Pacific slab beneath Kanto, Japan: Reactivation of subducted fracture zone?, Geophys. Res. Lett., 33, L16309, doi:10.1029/2006GL026773, 2006.

Nishimura, T., T. Hirasawa, S. Miyazaki, T. Sagiya, T. Tada, S. Miura, and K. Tanaka, Temporal change of interplate coupling in northeastern Japan during 1995-2002 estimated from continuous GPS observations, Geophys. J. Int., 157, 901-916, doi:10.1111/j.1365246X.2004.02159.x, 2004.

Ohta, Y., S. Miura, M. Ohzono, S. Kita, T. Iinuma, T. Demachi, K. Tachibana, T. Nakayama, S. Hirahara, S. Suzuki, T. Sato, N. Uchida, A. Hasegawa, and N. Umino, Large intraslab earthquake (2011 April 7 M 7.1) after the 2011 off the Pacific coast of Tohoku earthquake ( $M$ 9.0): Coseismic fault model based on the dense GPS network data, Earth Planets Space, 2011 (in press).

Ohzono, M., Y. Ohta, T. Iinuma, S. Miura, K. Tachibana, T. Demachi, and T. Sato, Detailed deformation associated with the 2011 off Pacific coast of Tohoku earthquake from a dense regional GPS network, in Japan Geoscience Union Meeting 2011, MIS036-P17, Chiba, Japan, 2011.

Okada, T., T. Yaginuma, N. Umino, T. Kono, T. Matsuzawa, S. Kita, and A. Hasegawa, The 2005 M7.2 MIYAGI-OKI earthquake, NE Japan: Possible rerupturing of one of asperities that caused the previous M7.4 earthquake, Geophys. Res. Lett., 32, L24302, doi:10.1029/2005GL024613, 2005.

Seno, T., K. Shimazaki, P. Somerville, K. Sudo, and T. Eguchi, Rupture process of the Miyagi-oki, Japan, earthquake of June 12, 1978, Phys. Earth Planet. Inter., 23, 39-61, doi:10.1016/0031-9201(80)90081-3, 1980.

Suwa, Y., S. Miura, A. Hasegawa, T. Sato, and K. Tachibana, Interplate coupling beneath NE Japan inferred from three dimensional displacement field, J. Geophys. Res., 111, B04402, doi:10.1029/2004JB003203, 2006.

Tobita, M., M. Ishihara, T. Imakiire, S. Ozawa, T. Kobayashi, H. Suito, A. Suzuki, T. Nishimura, Y. Noguchi, B. Miyahara, H. Munekane, M. Yamanaka, H. Yarai, M. Sato, and T. Ishikawa, Crustal deformation and fault model of the 2011 off the Pacific coast of Tohoku Earthquake, in Japan Geoscience Union Meeting 2011, MIS036-P21, Chiba, Japan, 2011.

Umino, N., T. Kono, T. Okada, J. Nakajima, T. Matsuzawa, N. Uchida, A. Hasegawa, Y. Tamura, and G. Aoki, Revisiting the three M 7 Miyagi-oki earthquakes in the 1930s: possible seismogenic slip on asperities that were re-ruptured during the $1978 \mathrm{M}=7.4$ Miyagi-oki earthquake, Earth Planets Space, 58, 1587-1592, 2006.

U.S. Geological Survey, Magnitude 9.0 - near the east coast of Honshu, Japan, http://earthquake.usgs.gov/earthquakes/eqinthenews/ 2011/usc0001xgp/, 2011a.

U.S. Geological Survey, Magnitude 7.1-near the east coast of Honshu, Japan, http://earthquake.usgs.gov/earthquakes/recenteqsww/ Quakes/usc0002ksa.php, 2011b.

Wessel, P. and W. Smith, New, improved version of Generic Mapping Tools released, Eos Trans. AGU, 79, 579, 1998.

Yagi, Y. and N. Nishimura, The 2011 Tohoku-oki Earthquake (Ver. 3), http://www.geol.tsukuba.ac.jp/ yagi-y/EQ/Tohoku/index-e.html, 2011.

Yaginuma, T., T. Okada, Y. Yagi, T. Matsuzawa, N. Umino, and A. Hasegawa, Coseismic slip distribution of the 2005 off Miyagi earthquake (M7.2) estimated by inversion of teleseismic and regional seismograms, Earth Planets Space, 58, 1549-1554, 2006.

Yamamoto, Y., R. Hino, K. Suzuki, Y. Ito, T. Yamada, M. Shinohara, T. Kanazawa, G. Aoki, M. Tanaka, K. Uehira, G. Fujie, Y. Kaneda, T. Takanami, and T. Sato, Spatial heterogeneity of the mantle wedge structure and interplate coupling in the NE Japan forearc region, Geophys. Res. Lett., 35, L23304, doi:10.1029/2008GL036100, 2008.

Yamanaka, Y., Off Fukushima-ken earthquake, 31 October 2003 
(M6.8), http://www.eri.u-tokyo.ac.jp/sanchu/Seismo_Note/EIC_News/ 031031.html, 2003 (in Japanese).

Yamanaka, Y., The Pacific coast of Tohoku earthquake on 11 March (M9.0), NGY seismological notes, 36, http://www.seis.nagoyau.ac.jp/sanchu/Seismo_Note/2011/NGY36.html, 2011 (in Japanese).

Yamanaka, Y. and M. Kikuchi, Source process of the recurrent Tokachioki earthquake on September 26, 2003, inferred from teleseismic body waves, Earth Planets Space, 55, e21-e24, 2003.
Yamanaka, Y. and M. Kikuchi, Asperity map along the subduction zone in northeastern Japan inferred from regional seismic data, J. Geophys. Res., 109, B07307, doi:10.1029/2003JB002683, 2004.

T. Inuma (e-mail: iinuma@aob.gp.tohoku.ac.jp), M. Ohzono, Y. Ohta, and S. Miura 